\title{
MERCEDES NÚÑEZ TARGA: \\ ESCREVER PORQUE SE TEM DE CONTAR
}

Joyce Rodrigues Ferraz-Infante*

“- Explica todo lo que has visto aquí. Que los de la calle lo sepan.

- Sí.

- No nos olvides.

- ¡Nunca!”

Mercedes Nuñez Targa

RESUMO: O objetivo deste trabalho é, a partir de uma breve contextualização de questões políticas e sociais relacionadas com o esquecimento e a recuperação da memória histórica na Espanha durante o período de democratização do país após a morte do ditador Francisco Franco, demonstrar de que forma a narrativa produzida no exílio contribuiu para a recuperação, a preservação e a transmissão da memória histórica relacionada à ditadura franquista. Para tanto, será feita uma sucinta apresentação da trajetória de Mercedes Núñez Targa, cuja reconstituição da própria vida por meio da escrita permite olhar criticamente não só para a Espanha ditatorial, mas também para a Europa nazifascista, já que a autora foi vítima de arbitrariedades em seu próprio país e na França invadida.

PALAVRAS-CHAVE: Literatura espanhola; Memória; Narrativa.

\footnotetext{
${ }^{*}$ Doutora em Letras pela Universidade de São Paulo (Usp). Professora Associada da Universidade Federal de São Carlos.
} 


\section{Pacto de esquecimento e dever da memória}

A memória histórica da Espanha referente aos anos da guerra civil (1936-1939), do pós-guerra e da ditadura franquista sofreu um duplo processo de silenciamento, forçado, inicialmente, pela política ditatorial de Francisco Franco, que, durante os quase quarenta anos em que permaneceu no poder, impôs apenas uma versão da história - a da Cruzada e da Vitória - ao reprimir, punir e calar os derrotados na contenda e os contrários ao seu governo, e, num segundo momento, pelo acordo tácito de silêncio firmado entre os partidos políticos espanhóis - e, supostamente, a população - durante o período conhecido por Transição Democrática ${ }^{1}$ com o propósito de manter a paz nacional e não comprometer o processo de democratização do país. Com essa intenção, a Ley de Amnistía - Ley 46/1977 aprovada em outubro de 1977 pelo Congresso de Deputados, concedia impunidade a todo e qualquer delito ou violação dos direitos humanos cometidos na Espanha antes de 15 de dezembro de 1976. Dessa forma, concederam-se indultos aos opositores do governo franquista que cumpriam penas em prisão por delitos políticos diversos - manifestações, organizações de grupos de resistência, atentados, etc. - e se absolveram de responsabilidades todos aqueles que durante a ditadura franquista cometeram crimes de abuso de poder repressão, tortura, prisão, desaparecimentos, etc. -. A anistia considerava, portanto, que havia havido algozes e vítimas entre opositores e defensores do franquismo e que a única forma de superar os traumas daquele passado recente, sem o risco de um novo embate, seria pelo perdão mútuo, pela reconciliação nacional e pela instauração de uma democracia "neutra", isenta do ônus e da responsabilidade de investigar e julgar o passado. Ao equiparar os delitos políticos da oposição antifranquista aos crimes da ditadura, a lei de anistia impediu a investigação e a apresentação dos fatos à sociedade, bem como o julgamento dos responsáveis pelos crimes franquistas, legitimando de certa forma - e segundo o entendimento de parte da população - os métodos e a violência política do regime de Franco.

1 Se conhece por Transição Democrática - Transición Democrática - um período de difícil determinação cronológica, que se inicia em 1975 com a morte de Franco, passando pela Constituição de 1978, e termina em 1982 com as eleições democráticas ou em 1986 com a inclusão da Espanha na Comunidade Europeia - 
Assim, se, por um lado, o acordo da transição favoreceu a implantação pacífica da democracia espanhola - apesar da frustrada tentativa de golpe de estado em 1981 -, por outro, frustrou a expectativa de parte significativa da população que esperava uma resposta da justiça às quatro décadas de violação dos direitos humanos na Espanha. Optou-se, oficialmente, por um pacto de silêncio; entretanto, no âmbito privado, familiar e coletivo - grupos e associações -, floresceu um movimento expressivo de recuperação e transmissão da memória republicana e antifranquista, que, no final dos anos 90, resultou no conhecido movimento de recuperação da memória histórica, que subitamente excedeu o espaço privado das famílias que buscavam os seus desaparecidos e irrompeu nos meios de comunicação e na esfera pública - jornalística, historiográfica, editorial, cinematográfica, artística, literária. Note-se que, paralelamente, observou-se a reincidência, com grande repercussão pública e midiática, de um discurso historiográfico neofranquista de legitimação do golpe de 1936 e da repressão na ditatura.

Segundo a historiadora Mercedes Yusta (2014), não é fácil situar com precisão as origens da emergência da memória dos vencidos nos meios de comunicação e no espaço público. Entre os acontecimentos marcantes e relacionados com o advento da memória da guerra civil espanhola estaria a homenagem aos sobreviventes das Brigadas Internacionais realizada em 1995 pelo Partido Socialista Obrero Español (PSOE), partido político no poder, e, no mesmo ano, a constituição de associações como a Asociación de Amigos de las Brigadas Internacionales e a Asociación para el rescate de la Memoria Histórica, que antecedem e inspiram a agrupação de outros coletivos que passaram a reivindicar publicamente o reconhecimento das vítimas do franquismo e da guerra civil do lado republicano. Assim, surge em 1997 a Asociación por un Archivo de la Guerra y el Exilio (AGE)² - que, além de reclamar a recuperação, conservação e difusão da memória histórica da guerra civil, foi

2 As principais reivindicações da AGE eram: a constituição de um arquivo centralizado da guerra civil e do exílio republicano, a anulação das sentenças do franquismo e o reconhecimento da dignidade dos combatentes republicanos - reivindicações que acata em parte a Lei da Memória Histórica de 2007. (YUSTA, 2014). 
pioneira em realizar de forma pública e com cobertura da mídia a abertura de fossas coletivas, nas quais se enterraram as vítimas da repressão franquista ${ }^{3}$-, e, desde 2000, a Asociación para la Recuperación de la Memoria Histórica (ARMH) que se dedica, entre várias outras atividades, à investigação, exumação e identificação, bem como ao reconhecimento de desaparecidos durante a guerra civil e ditadura. ${ }^{4}$

Os movimentos, as reinvindicações, as ações das associações de recuperação da memoria história repercutiram nos âmbitos social, cultural e político do país e culminaram em 2007 na popularmente conhecida Lei da Memória Histórica, "Ley 52/2007, de 26 de diciembre, por la que se reconocen y amplían derechos y se establecen medidas en favor de quienes padecieron persecución o violencia durante la guerra civil y la dictadura". Finalmente, a Espanha, depois de quase setenta anos, podia falar, expor e denunciar abertamente seu passado de violências, derrotas e traumas. Desse processo de recuperação e revisão da recente história espanhola, que a partir de meados dos anos 90 se estende a todos os âmbitos do país, participa de forma intensa e importante a literatura, sobretudo, a chamada narrativa de memória.

A memória, como bem observa Elizabeth Jelin, vincula passado com expectativas futuras, uma vez que "son experiencias pasadas que permanecen, se olvidan y se transforman en un interjuego con circunstancias presentes y expectativas futuras" (2002, p. 121). Para a autora, "transmisión, herencias y legados (como cosa dejada a alguien en testamento)

3 Segundo Mercedes Yusta (2014), a AGE foi a primeira associação a transformar em ato simbólico político e reivindicativo uma abertura de fossa comum: em 1998, na fossa de Canedo, no Bierzo, foram encontrados os restos mortais de quatro guerrilheiros abatidos pelas forças franquistas em 1941.

4 Dessa forma, de acordó com a historiadora Mercedes Yusta, "a la altura de 1998 ya estaba tomando forma el movimiento social que pronto se conocería como 'de recuperación de la memoria histórica', aunque en esos momentos sus actores tenían prioridades más políticas que memoriales. Para que ello se produjese se combinaron varios factores: la constitución de un corpus historiográfico consecuente sobre la guerra civil y la represión franquista, el tímido inicio de una política pública de memoria por parte del PSOE (y su rápido desmantelamiento por parte del PP una vez llegado al poder en 1996) y la urgencia biológica de muchos supervivientes de la guerra y la dictadura, que decidieron hacer de la reivindicación de sus derechos, olvidados por la democracia, el último de sus combates contra el franquismo. Ellos fueron en gran medida los impulsores de un movimiento al que pronto se sumó una nueva generación, los 'nietos', que han sido finalmente los portadores del movimiento al espacio público." (2014, p.30), 
suponen la inscripción de sentidos en un mensaje con la intención de preservación” (2002, p. 131). Nesse sentido, sociedade e instituições expressam de diferentes modos sua vontade de atuar sobre (preservar ou transmitir) as memórias com a tripla intenção de promover a justiça, de reconhecer e homenagear as vítimas, e de educar para o futuro. E ainda que alguns veículos sejam mais eficientes numa ou noutra direção, o mais comum, segundo Jelin, é que a vontade, a intenção e a estratégia se orientem para atingir esse triplo objetivo. Com efeito, a narrativa autobiográfica, a de testemunho, ou a narrativa ficcional fundamentada em pesquisas a arquivos pessoais, históricos, fotográficos ou fílmicos, se dispõem a reconstituir tramas individuais, sociais ou políticas com o propósito de transmitir e preservar memórias, de indagar causas e consequências do período traumático, de compreender o presente e proteger o futuro.

Por outro lado, ao termo "memória" se associam noções relacionadas à recordação de experiências vividas, a reminiscências do passado, lembranças vagas ou incompletas de sensações, imagens, sons, cheiros, histórias, palavras que evocam um tempo remoto do qual, no presente, se tem mais ou menos consciência; além de acepções ligadas à psicologia, fisiologia ou neurologia; o termo "memória" também remete a monumentos ou escritos sobre acontecimentos públicos ou históricos que não devem ser esquecidos. Nesse sentido, pode-se considerar como narrativa de memória tanto o relato de fatos do passado contados diretamente por quem sofreu ou viveu as experiências que rememora - narrativa de memória propriamente dita - quanto, por extensão, o relato de fatos do passado contados por quem não viveu diretamente as experiências, mas escutou histórias, colheu testemunhos, procurou recuperar lembranças familiares e públicas, realizou estudos e pesquisas para produzir o que seria também um discurso de memória - memória de segunda geração ou pósmemória (Sarlo, 2007, p. 92) -. De qualquer forma, devido à impossibilidade de se reconstituir fielmente o passado, toda narrativa de memória - própria ou alheia - é uma construção, uma representação, uma interpretação de lembranças, experiências ou fatos remotos. Por sua natureza, esse discurso pode se apresentar de forma fragmentária ou subjetiva, manifestar silêncios e vazios narrativos ou, ainda, preencher ou compor a realidade por 
meio da imaginação, uma vez que "é possível produzir um discurso imaginário sobre acontecimentos reais que pode não ser menos ‘verdadeiro’ por ser imaginário. Tudo depende de como se elabora a função da faculdade de imaginar da natureza humana", afirma Hayden White (2011, p. 483). Ressalte-se, ainda que, o tratamento de episódios traumáticos do passado implica amplas questões de índole ética e moral que evidenciam o comprometimento do escritor ou da escritora em relação ao tema.

Partindo dessas premissas, pretende-se demonstrar, na sequência, um exemplo de esforço de preservação da memória da repressão franquista realizado no exílio francês durante o período da própria ditadura. Destaque-se que enquanto o regime de Franco se esforçava por suprimir a oposição e a memória dela, essa resistência no exílio lutava por manter vivo o ímpeto e as lembranças dos que se opunham ao fascismo, fosse ele espanhol ou suas variantes europeias. Reestabelecida a democracia, o retorno do exílio, para muitos espanhóis, significou um compromisso com a recuperação e a transmissão da memória histórica contra o silêncio e o esquecimento.

\section{Escrever para contar}

Em Paris, abril de 1950, o número 36 do boletim Mujeres Antifascistas Españolas ${ }^{5}$, periódico mensal escrito por mulheres e para mulheres exiladas da Espanha franquista, comemorou o aniversário da proclamação da República espanhola em 14 de abril de 1931, destacando sua fundamental importância para que as mulheres espanholas trilhassem caminhos "que hasta entonces habían estado ocultos tras el muro de la tradición clerical y reaccionaria que mantuvo durante siglos a la mujer condenada a feudal servidumbre, alejada

\footnotetext{
${ }^{5}$ O periódico Mujeres Antifascistas Españolas, fundado em París em 1946 pela Unión de Mujeres Españolas, circulou até setembro de 1950 de forma clandestina. Idealizado por mulheres que participavam ativamente da resistência republicana no exílio, como Dolores Ibárruri, La Pasionaria, surgiu como forma de criar vínculos entre as mulheres espanholas desterradas, informar sobre o que ocorria na Espanha e fortalecer a resistência ao franquismo e ao fascismo. Misturam-se aos artigos e informações de teor político, receitas culinárias, dicas de beleza, moldes de costura, conselhos sobre a educação dos filhos, esses temas amenos de interesse geral serviriam de atrativo para as mulheres não engajadas nas causas políticas. (YUSTA, 2005).
} 
de todo lo que significa progresso, cultura, bienestar" (1950, p.4). Além de artigos relacionados à causa republicana espanhola e à situação do país sob o regime ditatorial de Francisco Franco, o boletim celebra as mobilizações de 8 de março, Dia da Mulher, traz informações de Cuba e da União Soviética, homenagens à aniversariante Dolores Ibárruri, La Pasionaria - responsável pela publicação do periódico - e habituais temas de interesse geral relacionados à costura, à cozinha, à beleza - que serviriam de atrativo para mulheres não engajadas nas causas políticas -, o boletim número 36 apresenta na página 13 os primeiros episódios de um relato intitulado "Dos años en las cárceles franquistas" que, por meio de um estilo narrativo acessível e sensível, pretende revelar às leitoras do periódico o cotidiano de uma das maiores prisões femininas do regime franquista. Introduzem o relato duas gravuras a lápis, no alto da página, assinadas por Ceballos, que retratam mulheres prisioneiras, de semblantes e ânimos murchos e atormentados, amontoadas em celas estreitas e mal iluminadas por estreitas janelas gradeadas, e, logo abaixo das gravuras, este breve prefácio introdutório:

\footnotetext{
"Hoy iniciamos la publicación de un relato de excepcional valor, por ser verídico, por haber sido vivido por una compañera nuestra durante dos años de encierro en las cárceles franquistas. Los hechos expuestos a continuación constituyen una acusación terrible contra el inquisitorial régimen del verdugo Franco. Pero son al mismo tiempo un exponente del maravilloso espíritu de las mujeres antifascistas, de su fe irrompible en la causa sagrada de la liberación de nuestra patria.

Por motivos fáciles de comprender, nos abstenemos de revelar el nombre de la autora de este relato." (Mujeres Antifascistas Españolas, 1950,36, p.13)
}

Note-se que o prefácio, além de esclarecer sobre a necessidade de manter em sigilo o nome da autora por motivo de segurança, destaca a veracidade da narrativa, bem como a determinação e a coragem de uma mulher que, como prisioneira política, vivenciou e testemunhou durante dois anos as atrocidades de uma prisão feminina franquista; atrocidades que pretende divulgar e denunciar por meio de seu relato. A prisão feminina de Ventas, Cárcel de Ventas, localizada na cidade de Madri e concebida em 1931 durante o período republicano para ser uma prisão modelo para mulheres, converteu-se a partir de 1939 num 
depósito de reclusas sem as mínimas condições de dignidade, higiene, saúde. Poucos meses depois do final da guerra civil espanhola, milhares de mulheres - menores de idade, idosas, grávidas, com filhos pequenos -, tachadas de "rojas" pelos vencedores franquistas foram condenadas a cumprir longas penas de reclusão, aguardar julgamentos ou esperar pelo cumprimento da pena de morte em Ventas e em várias outras prisões femininas espalhadas pelo país. Como bem observa Hernández Holgado, no caso das mulheres, o estigma "roja”, para além de uma opção política de esquerda, denotava subversão às tradicionais fronteiras sociossexuais que delimitavam os papéis desempenhados por homens e mulheres, já que para os adeptos do franquismo ousar romper os paradigmas de conduta feminina era um crime que deveria ser exemplarmente castigado (2003, p.121-131). Daí que se desejasse banir da sociedade - que o imaginário dos vencedores esperava construir - mulheres "rojas", milicianas, degeneradas, libertinas, irreverentes aos dogmas estabelecidos. A prisão de Ventas funcionou até 1969 no bairro de mesmo nome, na região leste de Madri, nas proximidades do cemitério do Este ou de La Almudena. Demolido o prédio, uma praça e edifícios familiares passaram a ocupar o seu lugar. Atualmente nada, nem uma placa, indica que outrora houve ali um presídio feminino. No entanto, na década de 1940, as presioneiras de Ventas, diariamente, escutavam de suas celas os disparos contra homens e mulheres, fuzilados nos muros do cemitério por terem se oposto ao golpe e ao regime de Francisco Franco. A autora de "Dos años en las cárceles franquistas" narra, no excerto "Fusilamientos en el cementerio del este", a primeira vez que ouviu da cela prisional o ruído da metralha, sem entender o que aquilo significava. Apesar de longo, o fragmento merece ser citado em sua totalidade:

"Me despierto sobresaltada. ¿Qué pasa? Hay un no sé qué en la expresión de todas las mujeres que me sorprende. Todas aguardan en silencio absoluto como si esperaran algo, los rostros llenos de emoción contenida. Hay labios que tiemblan, ojos que se enturbian... Por más que escucho atentamente, no oigo más que el ronroneo, amortiguado por la distancia, de un camión y el ladrido furioso de unos perros, pero no consigo establecer una relación entre eses sonidos, perfectamente normales y la actitud insólita de las mujeres. Intento preguntar qué ocurre, pero una voz enérgica me ordena el silencio. 
Bruscamente, se para el ruido del motor y es como si una ola de emoción indescriptible invadiera el pasillo. Una joven se cubre los oídos con ambas manos. La viejecita llora en silencio. Otra se muerde los labios hasta hacerse sangre.

¡Rrrran! El tableteo inconfundible de una ametralladora rasga el silencio. Y como torrente que se desborda, el pasillo se convierte en un coro de gritos, de llantos, de furiosas imprecaciones.

¡Asesinos!

¿Hasta cuándo, madre mía, hasta cuándo?

¡Canallas!

¡Silencio!. Y todas callan contiendo el llanto. (Continuará)"

(Mujeres Antifascistas Españolas, 1950, 36, p.14-15)

"(Continuación)

A lo lejos se oyen débilmente, a pequeños intervalos, unas detonaciones cortas y secas. ¡Los tiros de gracia!

¡Doce, quince, diez y ocho! — cuenta Catalina. Ayer fueron veinticuatro... ¡Y cada día lo mismo, cada día! ¿Es que no pararán nunca de matar?

La viejecilla de enfrente se enjuga las lágrimas temblorosa.

—Pobre "agüelilla"! — dice la campesina. Tiene dos hijos condenados a muerte. Tal vez son ellos..."

(Mujeres Antifascistas Españolas, 1950, 37, p.14)

Observe-se que, apesar de se tratar de um texto de memória que, como tal, pretende recriar por meio da narrativa experiências e sensações relacionadas a um passado traumático, a autora opta por utilizar o presente como tempo da narrativa. Por meio desse recurso, ao fazer coincidir o tempo da narração com o dos fatos narrados, cria-se um efeito de aproximação que serve tanto para facilitar a observação e a compreensão dos acontecimentos por parte do narrador como para aumentar a sugestão de realidade oferecida ao leitor.

Os excertos do relato "Dos años en las cárceles franquistas" - "Ventas", "Marianin", "Hambre”, “A diligencias", "El pátio de agua” -, foram publicados nas quatro últimas edições do boletim Mujeres Antifascistas Españolas, números 36, 37, 38 e 39, referentes aos meses de abril, maio, julho e setembro de 1950 quando o periódico saiu de circulação. Vale lembrar que, entre as publicações do derradeiro número 39, encontra-se um texto intitulado "Las trece rosas, heroínas de España". À semelhança das páginas de "Dos años en las cárceles franquistas”, uma ilustração a lápis bordejada de rosas, retrata, diante de grades de ferro, um grupo de meninas que, melancólicas e convictas, erguem o punho em gesto de 
resistência. As meninas que passaram para a história como Treze Rosas foram condenadas à morte pelo governo falangista por participarem das Juventudes Socialistas Unificadas (JSU)6, organização juvenil que durante a guerra civil espanhola mobilizou jovens para defender a República por meio de atividades de conscientização da população. A publicação não apresenta o nome da autora, mas a ilustração, o tema, o espaço em que se insere o narrador e o estilo do texto não deixam dúvidas de que se trata da mesma pessoa que escreveu a narrativa de memória "Dos años en las cárceles franquistas", como se pode depreender do seguinte fragmento:

Eran trece. La menor no había cumplido los 16 años. La mayor no pasaba de los veinte. Descubierta su valerosa actuación clandestina, gracias a la vil delación de una chivata - Carmen Vives Samaniego ingresaron en Ventas el mismo día: Ana Mari, Virtudes González, Conchita Conesa, Soledad, Blanquita... Atrozmente torturadas en la Comisaría, se portaron como auténticas J.S.U. $[\ldots]$

Erguidas, sonrientes, las trece rosas marcharon a la muerte con un "¡Viva la República!" en los labios.

Poco después, la descarga fatal las abatía en el próximo cementerio del Este. Blanquita quedó en pie; no había sido tocada. Fríamente, María Teresa, la fiera falangista le apoyó su pistola en la sien. Una detonación. El cinco de agosto de 1939, las trece rosas, símbolo de la juventud española, que prefiere morir que doblegarse ante el enemigo, habían escrito con su sangre uno de los primeros capítulos de la lucha heroica y silenciosa del pueblo español bajo la opresión franquista. [...].

(Mujeres Antifascistas Españolas, 1950, 39, p.11)

Apenas em 1967, Mercedes Núñez Targa deu-se a conhecer como a autora dessas memórias ao publicar em Paris - pela editora da Librairie du Globe, que criou o selo Colección Ebro com o objetivo de imprimir e divulgar títulos escritos por espanhóis exilados na França - o livro Cárcel de Ventas, que, numa versão ampliada e modificada pela própria Mercedes, inclui os textos aqui mencionados entre outros textos sem assinatura divulgados no boletim Mujeres Antifascistas Españolas.

6 Sobre as Juventudes Socialistas Unificadas (JSU) consultar o livro de Ricard Viñas, La formación de las Juventudes Socialistas Unificadas (1934-1936). 


\section{Mercedes Nuñes Targa nasceu em Barcelona em 1911 numa família de posses - o} pai, de origem galega, era dono de uma joalheria na conhecida Rambla de las Flores recebeu a clássica educação feminina da época - piano, francês, inglês... -, mas ao invés de seguir o caminho mais obvio para as moças de sua classe social, nos anos de 1930 começou a trabalhar como auxiliar de contabilidade e datilografia no Consulado do Chile em Barcelona e logo se interessa por questões sociais e políticas; proclamada a República em 1931, filiou-se às Juventudes Socialistas Unificadas (JSU) e quando eclodiu a guerra civil em 1936 passou a executar trabalhos burocráticos na sede do Comité Central do Partido Socialista Unificado da Catalunha (PSUC). Em janeiro de 1939, quando os falangistas ocuparam a Catalunha, mudou-se para La Coruña, Galiza, onde foi presa por agentes franquistas em novembro de 1939. Depois de passar pelas prisões de Betanzos e La Coruña, em março de 1940 foi transferida para a prisão de Ventas em Madri, onde permaneceu até janeiro de 1942, quando foi posta em liberdade provisória. Mercedes retornou a Barcelona e em setembro daquele mesmo ano cruzou os Pirineus com destino à França, utilizando a falsa identidade de Francisca Colomer. Na cidade de Carcassonne, Paquita Colomer - como era conhecida - se incorporou à Resistência francesa em luta contra o fascismo. Em maio de 1944, Paquita e seus companheiros de guerrilha foram presos. Depois de submetidos a interrogatório foram enviados a campos de concentração nazistas. Mercedes foi transportada para o campo alemão de Ravensbrück e depois enviada ao Kommando Hasag para trabalhar numa fábrica de mísseis ligada ao campo de concentração. Em abril de 1945, no dia em que estava listada para a câmara de gás, foi libertada por tropas aliadas americanas. Mercedes retornou à França em maio de 1945, onde retomou suas atividades militantes, oferecendo o seu testemunho sobre os processos de repressão franquista e nazista em diversos eventos e publicações escritas com e sem assinatura ou com vários pseudônimos. Além de Cárcel de Ventas, deixou também o seu testemunho sobre os campos de concentração nazistas no livro de memórias El carreto dels gossos publicado em catalão na cidade de Barcelona em 1980. Sobre os motivos que a levaram a escrever suas memórias traumáticas e sobre o seu compromisso com relação aos fatos e sentimentos que procurou rememorar 
e organizar em forma narrativa ela expõe na tradução ao castelhano de El carreto dels gossos, intitulada Destinada al crematorio:

Son los años treinta, y tengo yo veintitantos, cuando acabo de ler um livro corto y terrible: se titula En el campo de asisinos de Dachau y lo ha escrito Hans Beimler, aquel legendario Han Beimler de las Brigadas, que cayó en las trincheras de Madrid en 1936.

Lo leo apasionadamente, de un tirón, encogiéndome de hombros escéptica. Beimler se pasa de rosca. Los nazis son mala gente, de acuerdo, pero sin embargo...

Unos años más tarde, podré ver con mis propios ojos todo aquello del "campo de asesinos", y no como espectadora, sino como prisionera. Hans Beimler se había quedado corto.

Y ahora, ¿me vais a creer a mí? Quizás no. Pero es verdad y se tiene que escribir la verdad, aunque muchos, como yo misma en los años treinta, puedan encoger los hombros con escepticismo. Escribo porque se tiene que contar, aunque no sepa demasiado, con mi vocabulario empobrecido por el exilio; porque no se trata de hacer obra literaria, sino de decir la verdad. Y eso sí que lo haré. Me sacan de quicio los que cuando escriben sus memorias se muestran modestamente a sí mismos como los perfectos héroes, que nunca tuvieron miedo, que nunca pensaron en el "papeo”, ipuros espíritus!, que naturalmente estuvieron al frente de las acciones que salieron bien; pero que cuando hubo algún problema, ¡ah no!, ellos ya habían advertido que... Yo, no. Yo he tenido miedo, mucho miedo, e insensateces, también he hecho muchas; he pasado hambre e incluso he tenido deseos de quitarle la comida a una compañera. Todo os lo contaré y no haré trampa. (NÚÑEZ TARGA, 2016, p. 127-128)

Mercedes escreve suas memórias movida por uma questão ética e moral, "escribo porque se tiene que contar", para que se conheçam e não se repitam as histórias de um passado recente e tenebroso, e expressa o seu compromisso com a verdade, ainda que degradante, para que os leitores consigam avaliar os efeitos físicos e psíquicos das prisões nazistas - e falangistas - sobre o ser humano, mais especificamente, sobre mulheres de diversas faixas etárias, classes sociais, ideologias, mães, filhas, esposas.

Em 1975, morto Francisco Franco, Mercedes Núñez Targa retornou à Espanha com o propósito de divulgar seus testemunhos e histórias em instituições escolares, rádio, televisão, imprensa, eventos vários, colaborando, assim, para a recuperação da memória 
histórica da guerra civil e da ditadura espanholas e para a construção democrática do país. Faleceu em 1986 na cidade de Vigo, Galiza.

Entretanto, apesar da intensa militância contra o esquecimento de eventos traumáticos ligados a ideologias de natureza nazifascista, os principais escritos de Mercedes Núñez Targa, Cárcel de Ventas e El carreto dels gossos, pode-se dizer, não receberam na Espanha da Transição Democrática ou da Democracia a recepção que se esperaria a livros desse teor. A primeira edição do título sobre a prisão feminina de Ventas em território espanhol surgiu apenas em 2005, ou seja, quase quarenta anos depois do lançamento francês de 1967. Ademais, não se editou o texto original, mas sim uma tradução para a língua galega, Cárcere de Ventas, uma vez que a obra foi publicada na cidade de Vigo, Galiza. No mesmo ano, 2005, se reeditou em Barcelona El Carretó dels gossos. Una catalana a Ravensbruck, com prólogo de Pablo Iglesias Núñez, filho de Mercedes. Também em Barcelona, em tradução para o catalão, se publicou em 2008 o livro La presó de Ventas. Records d'una empresonada (1939-1942).

Considerando-se que Mercedes Núñez Targa é barcelonesa, filha de pai galego, e que sua vida na Espanha repartiu-se entre as regiões de Catalunha e Galiza, não seria de todo incorreto dizer que sua militância e obra permaneceram praticamente desconhecidas - ou silenciadas - no restante do país. Nesse sentido, apenas em 2011 se editou uma tradução castelhana do relato autobiográfico sobre a permanência de Núñez Targa no campo de Ravensbrück, Destinada al crematorio. De Argelès a Ravensbrück: las vivencias de una resistente republicana española, que, traduzido por de Pablo Iglesias Núñez, foi publicado em Sevilla.

Atente-se para o fato de que apenas em 2016 - passados cinquenta anos da edição francesa e trinta anos da morte da autora - se publica uma edição espanhola do original castelhano Cárcel de Ventas. Vale dizer que o livro, em língua castelhana, El valor de la memoria. De la cárcel de Ventas al Campo de Ravensbrück, reúne os dois livros de memória de Mercedes Núñez Targa sobre os anos de cativeiro na prisão de Ventas de Madri, de 1940 a 1942, e no campo de concentração de Ravensbrück, entre 1944 e 1945. O exemplar, além de prólogos e biografia da autora, traz uma série de fotos da época, documentos, mapas, que 
ampliam a sensação de verdade dos fatos narrados e contribuem para a compreensão da obra e a reconstrução do passado.

\section{A título de conclusão}

Como se pretendeu demonstrar, Mercedes Núñez Targa dedicou-se à tarefa de escrever e de reconstruir o passado traumático que lhe tocou viver com o firme propósito de contribuir para a preservação e a transmissão da memória histórica. Por meio de textos diversos e, sobretudo, da narrativa de testemunho, autobiográfica, se dispõe a recuperar e de algum modo reconstituir situações, sentimentos e sensações limítrofes, vividas ou observadas na prisão franquista e nos campos de concentração. Sua narrativa é busca de compreensão do vivido e é também incitação a que os leitores indaguem sobre as causas e as consequências dos eventos passados, para melhor lidar com o presente e preparar o futuro.

Esse rápido percurso pela vida e obra da autora procura minimamente diminuir o desconhecimento que ainda paira sobre sua trajetória e obra e, por extensão, o desconhecimento de uma maneira muito sensível e compromissada de pensar o passado espanhol e o trabalho de preservação da memória desenvolvido no exílio por tantas e tantos que como Mercedes Núñez Targa não se calaram.

\section{MERCEDES NÚÑEZ TARGA:}

\section{ESCRIBIR PORQUE SE TIENE QUE CONTAR}

RESUMEN: El objetivo de este trabajo es, a partir de una breve contextualización de cuestiones políticas y sociales relacionadas al olvido y a la recuperación de la memoria histórica en España durante el período de democratización del país tras la muerte del dictador Francisco Franco, demostrar de qué forma la narrativa que se produce en el exilio contribuyó para la recuperación, la preservación y la transmisión de la memoria histórica referente a la dictadura franquista. Para ello, se hará una sucinta presentación de la trayectoria de Mercedes Núñez Targa, cuya reconstitución de la propia vida por medio de la escritura permite mirar críticamente no sólo la España dictatorial, sino también la Europa nazifascista, ya que la autora fue víctima de arbitrariedades en su propio país y en la Francia invadida.

PALABRAS CLAVE: Literatura española; Memoria; Narrativa. 


\section{REFERÊNCIAS}

"Dos años en las cárceles franquistas". Mujeres Antifascistas Españolas, no 36-37-38-39, abril-octubre, 1950. Disponível em: https://prensahistorica.mcu.es/clandestina/es/publicaciones/numeros por mes.do?idPublicacion $=4541$ \&anyo $=1950$ Acesso em $25 \mathrm{de}$ maio de 2019.

HERNÁNDEZ HOLGADO, Fernando. Mujeres encarceladas. La prisión de ventas: de la República al franquismo, 1931-1941. Madrid: Marcial Pons-Ediciones de Historia, 2003.

JELIN, Elizabeth. Los trabajos de la memoria. Madrid: Siglo XXI, 2002.

NÚÑEZ TARGA, Mercedes. Cárcel de Ventas. Paris: Éditions de la Librairie du Blobe, 1967. Colección Ebro.

. El Carretó dels gossos. Una catalana a Ravensbruck. Barcelona: Edicions 62, 1980.

- Cárcere de Ventas. Trad. Carlos Arias y Sira Vidal. Vigo: A Nosa Terra, 2005.

. El Carretó dels gossos. Una catalana a Ravensbruck. Prólogo de Pablo Iglesias Núñez. 2 ed. Barcelona: Edicions 62, 2005.

. La presó de Ventas. Records d'una empresonada (1939-1942). Trad. Agnès Toda i Bonet. Barcelona: Cossetània Edicions, 2008.

- Destinada al crematorio. De Argelès a Ravensbrück: las vivencias de una resistente republicana española. Trad. Pablo Iglesias Núñez. Sevilla: Renacimiento, 2011.

. El valor de la memoria. De la cárcel de Ventas al campo de Ravensbrück. Sevilla: Renacimiento, 2016.

SARLO, Betriz. Tempo passado: cultura da memória e guinada subjetiva. Tradução Rosa Freire d'Aguiar. São Paulo: Companhia das Letras; Belo Horizonte: UFMG, 2007.

VIÑAS, Ricard. La formación de las Juventudes Socialistas Unificadas (1934-1936). Madrid: Siglo XXI, 1978.

WHITE, Hayden. "A questão da narrativa na teoria histórica contemporânea". Tradução de Bruno Gambarotto. In: Novais, F.A. e Silva, R.F. Nova história em perspectiva. São Paulo: Cosac Naify, 2011.

YUSTA RODRIGO, Mercedes. "El pasado como trauma. Historia, memoria y recuperación de la memoria histórica en la España actual”. Pandora: revue d'études hispaniques. Saint-Denis: $\mathrm{n}^{\circ}$ 12, 2014.

. La revista Mujeres Antifascistas Españolas, o la construcción de una identidad femenina comunista en el exilio francés (1946-1950). Pandora: revue d'etudes hispaniques, $\mathrm{n}^{\circ} 5$, 2005, p. 119-131. 
. "Género e identidad política femenina en el exilio: Mujeres antifascistas españolas (1946-1950)". Pasado y Memoria, no 7 (2008). ISSN 1579-3311, pp. 143-163.

Recebido em: 31/05/2019. Aprovado em: 30/07/2019. 